\section{ÖGIM FLIP}

Online publiziert: 14 Juni 2013

(C) Springer-Verlag Wien 2013

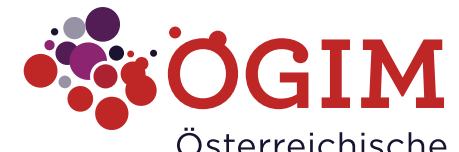

Österreichische Gesellschaft für Innere Medizin
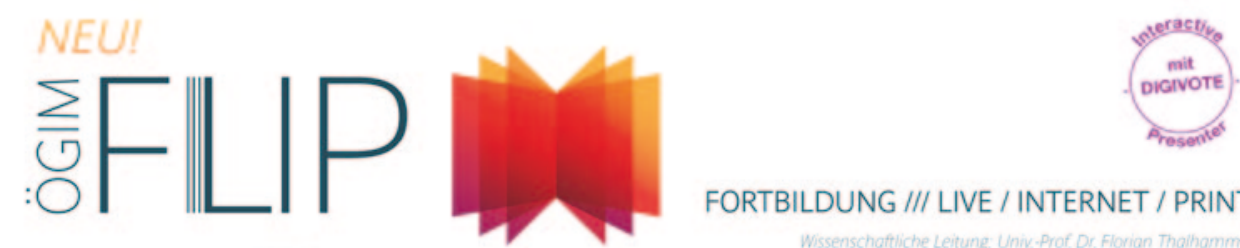

FORTBILDUNG /// LIVE / INTERNET / PRINT

Österreichs modernstes internistisches

Fortbildungsformat für alle fertigen

bzw. in Ausbildung stehenden FachärztInnen.

Online-fortbildung: www oegim-fip. at

Herz

Vorhoffimmer

Endokarditis

DD Rhythmustörunger

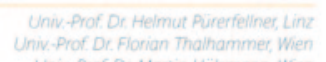

Univ. Prof. Dr Martin Hülsmann, Ween

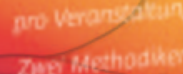

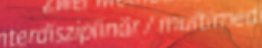

Online-fortbildung: www. oegim-flip. at

Lunge

Asthma und COPD

Blonchuskarzinom
DD Akuter Theranchmert

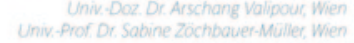

DD Akuter Thorarschmerz

Univ. Pror. Dr. Flarian Thalhammer When

Montog, 10. Juni 2013, 17.00-20.15

Niere

Arteriele Hyperton:

Nerenzeellkarzinon
DD Harndiagnostil

Zustitis und Prelonentritis

$\bullet$

Montag 23. September 2013, 17.00-20, 19

Darm

Antibiotika-assozierte Diarthoe

DD Akutes Abdomen

(inkl. Familares Mittelmeerfieber = FMW

Kolonkarzmom

conitis uicerosa und Morbus Crohn

Montog, 27. Oktober 2013, 17.00-20.15

DD Anàmie

Leukemlen

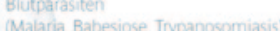

Univ-Pror De. Wortgang Reinhard Spert, Wen

Moderne Antikoagulationsoptionen

Prim Univ. Prof Dr Ansgar Wetermann, Linz

Montag, 11. November 2013, 17.00-20.15

Leber

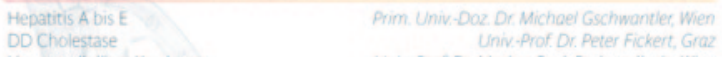

Hepatozellulares Karzinom

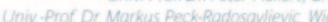

Informationen und kostenlose Anmeldung: www.oegim-flip.at

Raiffeisen-Forum Wien, Friedrich-Wilhelm-Raiffeisen-Platz 1, 1020 Wier
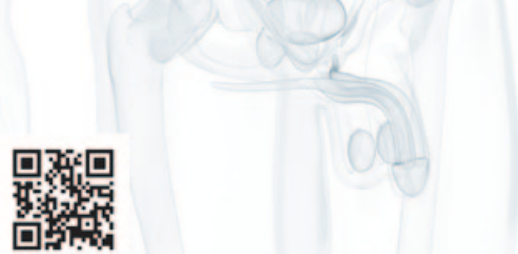

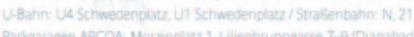

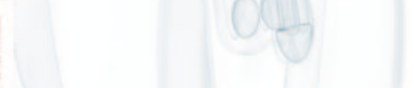

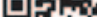

\%'MEDIZIN MEDIEN AUSTRIA

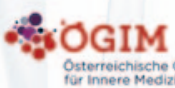

